Celso Antônio Bandeira de

Mello, doutor em direito e professor de direito administrativo na Pontíficia Universidade Católica de São Paulo - PUC -.

\title{
Relações entre Estado e entes descentralizados'
}

1. Conferência proferida na Costa Rica em setembro de 1981, durante seminário comemorativo do centenário do Colégio de Abogados da Costa Rica.

2. Exemplificativamente, é o caso do direito colombiano, conforme Alvaro Tafur Galvis em Las Entidades descentralizadas. Editorial Temis, Bogotá, 1977, p. $38 / 49$.
Introdução - A expressão ente descentralizado não é univoca. Mesmo tendo em mira apenas o fenômeno jurídico da descentralização administrativa - portanto, excluída a descentralização política operada nos Estados federais - pode-se tomá-la em mais de um sentido. As próprias sistematizações dos vários direitos positivos influirão no conceito de ente descentralizado.

Assim, desde logo, é possível considerar como tais, quaisquer pessoas governamentais que coadjuvam a ação da administração central, vale dizer, do conjunto orgânico do Poder Executivo. Neste caso, serão havidos entes descentralizados, tanto as autarquias (nominadas entes autônomos em alguns países), como as empresas do Estado, inclusive suas sociedades de capital misto com recursos particulares ${ }^{2}$. Procedendo-se deste modo, abarcar-se-á com o rótulo em apreço, quer pessoas de direito público (autarquias) e por isso submetidas a disciplina jurídica similar à da administração, quer pessoas de direito privado lou pelo menos assim consideradas em alguns países, como o Brasil) e que por isso mesmo estão regidas basicamente pelo direito privado, isto é, de modo visceralmente distinto das anteriores.

Diversamente, é possível entender que só devem ser considerados entes descentralizados as pessoas governamentais cujo regime jurídico seja administrativo, fundando-se em que 'administração pública', como conceito jurídico, deve embasar-se em sua relevância jurídica específica. E esta mede-se pela similaridade ou equivalência de disciplina jurídica, não por uma pretensa natureza essencial, 'a sestante', nem por um critério puramente subjetivo, orgânico.

A adotar-se este segundo entendimento, seriam entes descentralizados apenas as autarquias, excluindo-se da noção outras pessoas governamentais coadjuvantes do Executivo, porém estrutura- 
3. Tal como no direito costarriquense, a noção de autarquia, que equivale à de ente autônomo, não envolve poder legislativo algum. Assim, poderíamos, no direito brasileiro, sufragar inteiramente a afirmaçăo que Eduardo Ortiz y Ortiz faz ao respeito: "Los entes autônomos son una forma de la administración que ha dejado intocada la funcion legislativa..." - La Autonomia administrativa costarriquense, Separata da Revista de Ciencias Jurldicas. 1967, p. 122. das e disciplinadas basicamente segundo critérios e regras de direito privado.

De fora parte estas questões, outras podem prosperar em vista das classificações estatuídas pelas normas positivas de cada país, aliás, eventualmente, como é o caso do Brasil, procedidas sem critério uniforme ou internamente coerente.

Exemplificando, no direito federal brasileiro denomina-se Administração Indireta a realizada por autarquias, sociedades mistas e empresas públicas (art. 4. , n. II do Decreto-lei federal nः 200, de 25 de fevereiro de 1967). Estas duas últimas são qualificadas como pessoas de direito privado (art. 5\%). Excluem-se da noção de Administração Indireta, sem nenhuma razão plausível, as Fundações Governamentais que são, tanto como as sociedades mistas e empresas públicas, categorizadas como pessoas de direito privado e, tal como elas, entidades que desempenham misteres auxiliares da Administração.

Por outro lado, fazendo não coincidir a noção de Administração Indireta com a de descentralização administrativa, o mesmo diploma federal (Decreto-lei n. 200, de 25 de fevereiro de 1967) estatui que a descentralização será feita mediante delegação de competência, convênio com as entidades federadas e contratos e concessões com os particulares (art. 10, §1\%).

Deixando de lado esta grave impropriedade, vê-se que a noção de Administração Indireta do direito brasileiro aproxima-se ou coincide com as noções mais correntes da doutrina sobre descentralização administrativa.

Não obstante tenhamos firme preferência por um critério sistematizador que leve em conta o regime jurídico da pessoa como matriz classificatória, vamos nominar de entes descentralizados todas as pessoas que coadjuvam a ação própria do Executivo, independentemente da paridade de regime disciplinador da entidade.

Cremos que sendo esta a acepção mais frequëntemente acoIhida, deve ser a eleita para os fins da presente exposição. Além disto, em face da íntima correspondência entre os conceitos de Administração Indireta do direito brasileiro e o de entes descentralizados, mais generalizadamente aceito, vamos discorrer sobre as relações entre o Estado e as pessoas da Administração Indireta. Assim, não obstante a diferença de rotulações, haverá, quando menos, aproximada coincidência de objetos.

Cumpre, apenas, esclarecer qual o conceito de cada uma destas figuras tipológicas que compõem o panorama das entidades de administração indireta federal no Brasil. Vamos enunciá-las tomando por base as noções correntemente admitidas no país, sem apego à literalidade das definições legais - incrivelmente mal formuladas - mas fixados na interpretação prevalentemente para compreensão das referidas definições.

Entende-se por autarquia a pessoa jurídica de direito público, criada por lei, de capacidade exclusivamente administrativa ${ }^{3}$, que 
exerce, pois, atividades reputadas típicas da Administração Central, mas que, para melhor funcionamento, requerem gestão administrativa e financeira descentralizada. São havidas como um serviço autônomo, com patrimônio e receita próprios.

Considera-se empresa pública a pessoa de direito privado, formada exclusivamente com capitais de origem governamental e em que a totalidade das ações ou a maioria acionária votante pertenca à União ou à pessoa de sua administração indireta, criada por lei e com a finalidade de explorar atividade econômica ou de prestar serviço público.

Qualifica-se como sociedade de economia mista a pessoa de direito privado, constituída sob a forma de sociedade anônima, cujas ações com direito a voto sejam majoritariamente da União ou entidade de sua Administração Indireta e, minoritariamente, de particulares, criada por lei para explorar atividade econômica ou para prestar serviço público.

Ao se cogitar das relações entre o Estado e as entidades descentralizadas, o principal tema que acode ao espírito é o do controle destas pessoas. Sem embargo, há outros aspectos jurídicos interessantes e pertinentes que também merecem referência. Entendemos cabível examinar os seguintes tópicos: criação e extinção dos entes descentralizados; relações tributárias entre Estado e entes descentralizados; controle dos entes descentralizados e responsabilidade patrimonial do Estado por atos dos entes descentralizados.

É evidente que estes diversos itens comportariam, cada qual, alongada exposição. Nada obstante vamos cifrar-nos a uma brevíssima dissertação, adstritos ao objetivo de exibir, panoramicamente, o tratamento jurídico cabível no direito brasileiro, para estes distintos problemas.

\section{Criação e extinção dos entes descentralizados}

No Brasil prevê-se que os três tipos de entes descentralizados - nominados pessoas da Administração Indireta, como se viu são criados por lei. Assim, resulta claro que nenhum ato administrativo teria força para entronizá-los no universo jurídico. Pensamos inclusive, que em qualquer país onde se adote sem reservas o principio da legalidade descaberia outra solução. Com efeito, instaurar uma nova pessoa governamental, fragmentando, assim, a unidade orgânica na prestação de atividades que, em princípio, incumbem à pessoa do Estado, (por via da administração), é ato de extremo relevo. Por isso, só mesmo preceito de hierarquia superior, como o é a lei, poderia decidir sobre tal matéria.

Tendo-se em mira que a atividade da administração é, por definição, atividade subordinada, não seria de admitir solução diversa.

A dúvida interessante que pode surdir substancia-se no seguinte: é necessário que uma lei crie formalmente uma empresa pública ou sociedade de economia mista ou pode-se considerar preenchido este requisito, por via indireta? Por exemplo: se a lei autorizar que o Executivo desaproprie a totalidade ou a maioria das ações de 
uma empresa particular, haverá surgido empresa pública ou sociedade mista com a efetivação da medida?

Estamos em que a resposta deverá ser afirmativa. Com efeito, a autorização para expropriar valerá, no caso, como deliberada intenção, exprimida pelo Legislativo, de assumir a entidade privada, convertendo-a em instrumento de ação estatal. Desnecessário, pois, que esta manifestação clara, assuma o enunciado formal de declarar criada a pessoa governamental.

Outrossim, embora a lei brasileira fale em 'criação por lei', entendemos que, em rigor, a linguagem textual deve ser interpretada como 'autorização legal para criar'. E a razão disto está em que sempre no caso das sociedades mistas e empresas públicas tratando-se de pessoas constituídas na forma do direito privado, o modo pelo qual passam, de direito, a existir é com o registro de seus estatutos, segundo dispõe o próprio direito brasileiro.

Diversamente, no caso das autarquias, pessoas de direito público, parece-nos que ganham existência, perante o direito, a partir da lei criadora. Os atos sucessivos - incumbentes à Administração - de mobilizar recursos para integrá-los materialmente no patrimônio da novel entidade, de designar o pessoal e quejandos, são meras providências práticas para sua efetiva instituição no plano das realidades empíricas. Contudo, no reino do direito, a autarquia existe desde a lei criadora.

Outro ponto suscetível de gerar controvérsia atina à possibilidade (ou impossibilidade) e as conseqüências de uma sociedade mista ou empresa pública virem a criar, por si mesmas, outras sociedades, prevalecendo-se da desenvoltura que Îhes é conferida por sua estrutura de direito privado.

É ao fruto destas decisões que se tem atribuído o nome de empresas do Estado 'de segunda geração' e, às vezes, até mesmo, 'de terceira geração'.

Em rigor haveria que separar duas hipóteses: casos em que a lei originadora da empresa estatal-mãe Ihe confere autorização para criar empresas subsidiárias e casos em que a lei não contempla tal autorização. Haveria, ainda, que perguntar se o regime das empresas-filhas seria ou não o das empresas-mães, isto é, se estariam submetidas ao mesmo esquema de relações entre Estado e entes descentralizados e entre estes e terceiros.

Pensamos que é legítima a criação de empresas estatais subsidiárias apenas quando a lei fundante da empresa estatal matriz (a) autoriza este proceder e (b) especifica as finalidades parciais que serão da alçada das subsidiárias. Isto porque, sem o primeiro requisito (autorização legal antecipada) a empresa do Estado não teria calço jurídico algum para este proceder. Se à própria administração central, da qual ela é auxiliar, não se reconhece o poder de criar, por decisão própria, uma nova pessoa jurídica, como reputar cabível que mera empresa estatal o faça?

De nada valeria argumentar que seu caráter privado defere-lhe maior liberdade de manejo, mais desatado comportamento do que 
o pertinente à Administração, peada que é, esta última, pelas regras de direito público. A lógica aparente deste raciocínio descansa no equívoco de presumir que a outorga de personalidade privada infunde-lhe natureza igual à das empresas particulares.

A atribuição desta espécie de personalidade é simples recurso para agilizar a atuação do Estado na busca de certos cometimentos havidos como de interesse de toda a coletividade. Não é, de modo algum, procedimento que possa, legitimamente, permitir ao Executivo costear os limites e contenções derivados do mecanismo de relacionamento entre os poderes do Estado. Posto que a atividade administrativa, no Estado de direito, deve ficar encasulada no quadro normativo estabelecido por lei, seria intolerável que, por vias transversas, superasse este obstáculo.

$\mathrm{O}$ certo é que as empresas do Estado têm insculpidas em sua essência o serem nada mais que instrumentos auxiliares do Executivo, pessoas estatais, agentes de propósitos reputados úteis para a coletividade e incumbentes à Administração. Não se deve, pois, extrair da outorga de personalidade privada, conclusão desbordante da razão de ser desta outorga, a qual cifra-se a permitir atuação mais solerte e expedita, similar à das empresas privadas, quanto às relações com terceiros. Assim, seria incabível que empresa do Estado pudesse, sem preliminar autorização legal, gerar novas pessoas.

Outrossim, caso a lei lhe franqueasse, preliminarmente, a geração de outras pessoas, seria necessário que, neste ato autorizador, fossem indicadas as finalidades parciais, enquadradas no plexo de objetivos da empresa-mãe, suscetiveis de serem cometidos à empresa de segunda geração. É o mínimo que se pode requerer, para persistir configurada a senhoria do Legislativo sobre o surgimento de novas entidades instrumentais do Estado.

$O$ regime destas pessoas, assim surgidas, consoante nos pare$c e$, haveria de ser o mesmo da empresa geradora. As razões que compareceram para fundamentar as soluções precedentes aplicamse, por iguais motivos, ao caso em pauta.

No direito brasileiro, em nivel infralegal prevê-se que o Executivo pode extinguir, por ato seu, as empresas do Estado que apresentem prejuízo prolongado (art. 178 do Decreto-lei n. 200). Ao nosso ver a solução é inconstitucional.

A extinção das empresas do Estado só pode ocorrer por insolvência dela ou por determinação legal. De fato, ou seu desaparecimento resultará de uma circunstância incontrolável, alheia à vontade da própria sociedade ou, então, por deliberação do legislador. Realmente, seria inadmissivel que à vontade de seus dirigentes ou do Executivo se atribuísse o poder de desfazer algo que foi produzido em conseqüência de uma vontade superior: a legal. Segue dai que o art. 178 do Decreto-lei n. 200, segundo o qual o Executivo poderá liquidar ou incorporar a outras entidades (respeitados os direitos assegurados aos eventuais acionistas minoritários) as sociedades em que detenha maioria acionária que acusem prejuizo continuado, é de valor jurídico nulo. 
4. Estudos de direito administrativo, Atlântica Editora, Coimbra, 1968, p.9.

5. Espelham bem a situação juridica da administração, os seguintes excertos: "Administrar é aplicar a lei de ofício" (Seabra Fagundes, Controle dos atos administrativos pelo poder judiciário, Editora Forense, Rio de Janeiro, 3 ed., 1957, p. 17. "A actividade de administração é uma actividade de subsunção dos fatos da vida real às categorias legais" (Afonso Rodrigues Queiró, A Teoria do desvio de poder em direito administrativo, Coimbra Editora, 1940, p. 19.

6. Disse com propriedade Ruy Cirne Lima: "O fim e não a vontade domina todas as formas de administração. Supõe destarte a atividade administrativa a preexistência de uma regra jurídica reconhecendo-lhe uma finalidade própria. Jaz, conseqüentemente, a Administração Pública, debaixo da legislação que deve enunciar e determinar a regra de direito" (Princlpios de direito administrativo, Ed. Sulina, 1954, 3 ed. p. 22).
Com efeito, em nosso sistema constitucional só a lei tem força inaugural no sistema jurídico, cumprindo ao Executivo, como servo obediente dela, tão-só e unicamente cumprir-lhe a vontade. $\mathrm{O}$ art. 81, item III, da Carta Constitucional, indica bem claramente que ao Presidente da República incumbe expedir decretos e regulamentos para "fiel execução das leis". O art. 82, item VII, proclama ser crime de responsabilidade do Presidente da República praticar atos que "atentem contra o cumprimento das leis". 0 art. 153, § 2., declara que "ninguém será obrigado a fazer ou deixar de fazer alguma coisa senão em virtude de lei". O próprio decreto-lei (art. 55), utilizável em condições excepcionais pelo Executivo - pois só é facultado em casos de urgência ou de interesse público relevante e desde que não haja aumento de despesa, limitado, ainda, a matérias restritas submete-se à aprovação do Congresso Nacional.

Os diferentes artigos citados estão a mostrar, de acordo aliás com a melhor tradição do direito brasileiro e que ainda persiste por não ter sido totalmente violentada, que a posição do Executivo em nosso sistema constitucional é francamente subalterna, como convém que seja nos regimes democráticos, cabendo ao Legislativo dar o impulso inicial a todo comportamento estatal, de tal modo que reste ao Executivo o papel, que bem Ihe calha, de agente material cumpridor de vontades superiores, decididas em escalão mais alto, em nivel de representação popular nacional.

Não basta, então, um Decreto-lei çonferir ao Executivo o poder de desfazer o que foi feito por lei, pois o art. $6^{\circ}$, parágrafo único do texto constitucional brasileiro, proíbe expressamente a qualquer dos poderes delegar a outros atribuições que lhe são próprias, salvo exceções previstas na própria Carta Magna. Com muito maior razão, é vedado a um dos Poderes atribuir-se a si próprio competências que a Lei Maior outorga a outro. Daí que Decreto-lei não pode irrogar o Executivo em poderes próprios do Legislativo.

Quanto à extinção dos entes autônomos, designados como autarquias no Brasil, tem-se por certo e pacífico que só por lei podem ser extintos. Deveras, o que nasceu por decisão legal, só por decisão legal pode ser desfeito.

Cabe insistir em que a administração é atividade sublegal, serviente, instrumental. Como bem o disse o professor luso Afonso Rodrigues Queiró, a administração é a longa manus do Legislativo ${ }^{4}$.

Importa considerar que a manifestação sobranceira da vontade do Estado é a lei. Só através dela inaugura-se uma ordem jurídica primária, fundada apenas na Constituição. O trabalho posterior, incumbente à Administração, é o desenvolvimento, promoção e execução dos atos subseqüentes, comportados na previsão genérica da lei e cujo valor jurídico depende precisamente desta adequação. Por isso mesmo o 'motor', se cabe dizer, a seiva de vitalidade jurídica destes atos posteriores é o mandamento legislativo que se visa pôr em prática e a que se reportam implícita ou explicitamente.

$\mathrm{O}$ mundo da administração é infralegal ${ }^{5}$. Tem sua origem e apoio na finalidade legalmente consagrada ${ }^{6}$. Como todo o dinamis- 
7. Vale registrar a antiga e sempre atual lição de Fritz Fleiner: "Administração legal, então, é aquela posta em movimento pela lei e exercida dentro dos limites de suas disposições" (Principes généraux du droit administratif allemand, Librairie Dellagrave, Paris, 1933, trad. Ch. Einsenmann, p. 87). mo da administração advém do dever de prosseguir o disposto na lei ${ }^{7}$, assim como é requerida lei para fraturar a unidade orgânica administrativa e dar origem aos entes autônomos, também é requerida para fazer cessar-Ihes a existência.

Havendo o Legislativo criado ente autônomo para o cumprimento de determinado fim, nem o Executivo, nem a própria pessoa autárquica podem aniquilar aquela existência jurídica, pois a nenhum dos dois assiste o poder de decidir sobre a matéria. A ambos compete simplesmente obedecer. Dar seguimento à finalidade prevista. Quem a fixou, quem estabeleceu o modo de cumpri-la e quem tem controle sobre isto é tão-somente a lei.

\section{Relações tributárias entre Estado e entes descentralizados}

No direito brasileiro, por decisão constitucional, a tipologia básica dos tributos é tripartida, compreendendo: impostos, taxas e contribuição de melhoria.

Impostos são as prestações tributárias não vinculadas a uma contraprestação específica do Poder Público. Ė dizer, não vinculadas a uma atuação específica do Estado. Taxas são as prestações tributárias vinculadas a uma atuação específica do Poder Público em relação ao contribuinte. Contribuição de melhoria são as prestações tributárias devidas em decorrência de uma valorização imobiliária produzida por obra pública.

Os entes autônomos, no Brasil designados com o nome de autarquia, são constitucionalmente imunes a impostos. Sujeitam-se, contudo, a taxas e contribuição de melhoria. Antes de haver dispositivo constitucional explícito consagrando esta solução, já era adotada, por interpretação, a mesma inteligência, pois a Lei Magna estabelecia imunidade recíproca a impostos entre União, Estados federados e municípios. Partindo-se do correto pressuposto de que o ente autônomo é um desdobramento personalizado (público) do Estado em sua feição administrativa, entendia-se que às autarquias comunicavam-se os benefícios genéricos que a ordenação jurídica defere ao próprio Estado.

Este tema, evidentemente, é de particular relevo em Estados federais, posto que em Estados unitários, por razões óbvias, não há entrechoque de pessoas oriundas de distintas ordenações jurídicas internas.

Caberia, entretanto, indagar se nestes a solução cabível seria a mesma ou diversa, sobretudo no caso, qual o da Costa Rica, em que há dispositivo, na própria Constituição (art. 189), atribuindo a qualidade de entes autônomos para certas entidades.

Ousamos opinar no sentido de que não havendo impediente constitucional à tributação, caberia apenas à lei decidir especificamente sobre a matéria. A falta de disposição legal específica em relação a eles presumir-se-á isenção de impostos.

A razão da opinião expressada reside em que, sendo os entes 
8. Horacio Heredia distingue controle parlamentar de controle legislativo. Para o autor citado, controle parlamentar é gênero e controle legislativo é aquele que se exerce mediante atos em forma de lei (Contralor administrativo sobre los entes autárquicos, Buenos Aires, 1942, p. 22). autônomos de natureza pública, não é de pressupor que o Estado pretenda, salvo inequívoca manifestação do Legislativo, sacar-Ihe recursos que, de outra sorte, estariam aplicados ao desempenho de um mister igualmente público. Não cremos cabível presumir que se haja fracionado a unidade administrativa do Estado para, ao depois, recolher, da entidade pública criada, recursos cuja utilização considerou-se conveniente deferir-lhe.

A questão das relações tributárias assume diversa feição no caso de pessoas estatais constituídas na forma do direito privado. Estas, tanto podem ter sido criadas para a prestação de um serviço característicamente público, quanto para explorar atividade econômica, seja em regime de monopólio, seja em paralelismo com a inciativa privada.

Se a entidade é prestadora de serviço público propriamente dito, entendemos que a lei 'pode' dispensá-la de impostos. Se não o fizer estará adstrita à situação jurídica dos demais contribuintes, pois a tipologia de direito privado que lhe foi atribuída reclamaria esta solução.

Se a entidade exercita atividade econômica em paralelismo com a iniciativa privada, estamos em crer que não lhe pode ser concedido favor fiscal algum nos países cujo sistema esteja estribado na livre iniciativa, salvo se extensivo às empresas privadas do mesmo ramo de atividade. Isto porque privilegiá-las corresponderia à inversão da tônica do sistema, pois conferiria a quem exerce atividade suplementar ou ancilar, prevalência em relação a quem está operando em domínio preponderantemente seu. A solução em causa está, no direito brasileiro, expressamente prestigiada no art. $170, \S \S 2$. e $3^{\circ}$, da Carta Constitucional.

Se a entidade exerce atividade monopolizada, contudo, não haveria óbice a outorgar-Ihe favor tributário, pois daí não resultaria qualquer desequilíbrio em relação às empresas privadas, dada a impossibilidade de comparecerem no setor.

\section{Controle dos entes descentralizados}

Este é certamente o ponto crucial das relações entre o Estado e os entes descentralizados. Ainda que existam vários pontos comuns no controle dos entes autônomos (autarquias) e das pessoas descentralizadas que têm, no direito brasileiro, personalidade de direito privado, parece oportuno, a bem da clareza expositiva, separar as questões. Mencionaremos primeiro o controle das autarquias e depois o das empresas do Estado.

Demais disso, separaremos o controle administrativo, é dizer, - efetuado pela própria Administração Central, do controlé parlamentar ${ }^{8}$, efetuado por órgão auxiliar do Legislativo: no Brasil, pelo Tribunal de Contas e na Costa Rica pela Contraloria General de la República.

Ao estruturar um sistema administrativo que supõe desdobramento da Administração, o Estado, por meio de lei, estabelece os mecanismos de articulação entre a pessoa autônoma e a Adminis- 
9. Alguns autores usam a expressão vigilância para reportarse ao controle de legitimidade e reservam a palavra tutela para o controle de mérito. Assim, por exemplo, Arnaldo de Valles (Elemento do dirltto amministrativo, 3 ed., 1956, p. 89), Renato Alessi ISistema istituzionale del diritto amministrat/vo italiano, 1953, p. 138 e 139). Quanto a nós servímonos da expressão em seu sentido amplo, abarcando tanto o controle de legitimidade como o de mérito. Assim procedem em geral os autores franceses, como por exemplo Jean Rivero (Droit administratif, 2 ed., 1962, p. 277 a 279), A. de Laubadère (Traité de droit administratif, 3 ed., 1963, vol. I, p. 90 e segs.), George Vedel (Droit administratif, 2 ed., 1958, vol. II, p. 418).

10. Direito administrativo, Lisboa, 1963,6ed., p. 172. tração Central, fixando um sistema de relacionamento entre ambos, consubstanciado no controle administrativo, ou tutela ${ }^{9}$.

O controle administrativo ou tutela é o conjunto de atos que a administração central pratica - dentro dos limites autorizados no sistema legal - a fim de conformar os entes autônomos ao cumprimento de seus fins próprios. Ė, pois, um poder de influir sobre eles.

Por meio do controle, o Executivo ajusta-lhes o comportamento às exigências legais, harmonizando sua atuação com os objetivos públicos em vista dos quais foram criados.

Não se confunde o controle com a hierarquia. $O$ ente autônomo não é subordinado à administração central, pois sua criação traduz, justamente, uma ruptura da linha hierárquica unificadora do aparelho administrativo.

Os dois institutos se diferenciam em que a hierarquia é vínculo de autoridade que define um comando permanente, contínuo e sobre a totalidade da atividade dos órgãos e agentes situados em escaIão inferior. Então, por ser o meio normal estruturador da administração, assecuratório de sua unidade, os poderes do hierarca se presumem. A existência do liame de subordinação, com suas inevitáveis decorrências, é conatural ao esquema organizativo da Administração Central.

Já o controle ou tutela circunscreve-se aos atos previstos em lei e emerge nos casos e hipóteses nela prefigurados. Em conseqüência não é constante, nem contínuo, nem abarca a totalidade dos atos da entidade autônoma. No direito francês, valem-se os doutrinadores de uma frase padrão para caracterizar a natureza estrita da tutela. Afirmam: "Pas de tutelle sans texte, pas de tutelle au delà des textes".

Marcelo Caetano esclarece: "Os poderes da tutela administrativa não se presumem". Os atos das autarquias "só estão sujeitos à tutela nos termos expressamente fixados na lei, isto é, apenas os atos que a lei dispuser, pela forma e para os efeitos estabelecidos e pelos órgãos ai designados" 10 .

Por isso se pode dizer que a tutela existe 'quando', 'como' e 'na forma expressamente prevista' em lei.

Compreende-se que assim seja: se a lei houver por bem fraturar a unidade da administração, se considerou que a forma conveniente de prestação de certos serviços se realiza pela exclusão deles da linha hierárquica, não pode o Executivo, por vontade própria, sem calço legal, recompor liames que o Legislativo entendeu oportuno romper.

Exercer o controle fora das hipóteses previstas equivale, simplesmente, a insurgir-se contra a lei.

Sem embargo, o diploma criador da entidade autônoma, ou outro posterior, podem, evidentemente, estabelecer um controle intensíssimo sobre ela, outorgando à Administração Central extensos poderes. 
O controle pode ser 'preventivo' ou 'repressivo' e concernente ao mérito dos atos da autarquia ou restrito à 'legitimidade deles'.

Controle 'preventivo' é aquele em que a administração central exerce seu poder de contraste antes da produção do ato da entidade autônoma ou da eclosão de seus efeitos jurídicos. Tem lugar quando esta deve, previamente submeter à concordância da Administração Central o ato que pretende expedir ou quando, embora já produzido, o ato tem sua eficácia condicionada à concordância da Administração Central.

No primeiro caso, sobre ser preventivo, é a priori, no segundo, conquanto preventivo, é a posteriori. Em ambos contudo - e por isso se diz preventivo - o controle previne o desencadeamento de efeitos jurídicos em desconfomidade com o pronunciamento da Administração Central. Expressa-se por meio de autorização, aprovação ou homologação, conforme o caso, isto é, na dependência do que a lei estabelecer.

Controle 'repressivo' é aquele em que a Administração Central exerce seu poder de contraste após a produção de um ato cuja eficácia independe de prévio pronunciamento dela. Configura-se como manifestação corretiva, através da qual a administração central reprime uma atuação da autarquia produzida de modo conflitante com seu juízo. Manifesta-se através do poder de revogar, modificar ou anular o ato da entidade autônoma.

Controle de 'mérito' é aquele em que é dado à Administração Central contrastar o ato sob o ponto de vista da conveniência ou oportunidade. Assiste-lhe, no caso, o poder de exprimir um juízo discricionário, preventivo ou repressivo, conforme o estabelecido em lei, mediante o qual concordará, ou não, com o ato.

Controle de 'legitimidade' tem lugar quando o poder da Administração Central cinge-se ao exame da legitimidade do ato. Nesta hipótese, a ação controladora vai se restringir à verificação da conformidade ou desconformidade do ato com as exigências do sistema normativo, atendo-se, pois, à lisura jurídica dele, donde se tratar de exame vinculado. Todas as modalidades de controle referidas, excusa dizer, existem conforme o estabelecido em lei, isto é, desde que previstas e segundo o modo nela fixado.

A fim de exercer tutela, sobretudo quando esta é apenas repressiva, necessita a Administração fiscalizar, mantendo sob sua inspeção o comportamento das entidades autônomas. Trata-se, pois, de um poder natural e que pode ser espontaneamente exercido pelo órgão central encarregado do controle. Efetivamente, quem dá os fins não pode negar os indispensáveis meios; ainda quando a lei não preveja expressamente a fiscalização, o órgão da Administração Central a que estiver vinculada a pessoa autônoma, pelos liames do controle, pode sempre e a qualquer instante manter-se informado sobre os atos da entidade, fiscalizando sua atuação.

A tutela de que tratamos até agora denomina-se 'ordinária', porque prevista em lei. Exercita-se com normalidade. Há, contudo, em situações anômalas e extremas, a admissibilidade de uma tutela 
11. Horacio Heredia - Contralor administrativo sobre los entes autarquicos, Buenos Aires, p $61 / 62$. 'extraordinária', assim denominada por ser exercitável mesmo à falta de previsão legal, quando circunstâncias especialmente graves exijam, imponham, ação corretiva da Administração Central, se o ente autônomo incidir em grave distorção em seu comportamento ${ }^{11}$.

Finalmente, cabe registrar que, em casos excepcionais, de suma gravidade, compete à Administração Central, por meio do órgão a que esteja ligada a pessoa autônoma, promover 'intervenção' nela, substituindo-se a seus dirigentes, quando a entidade haja se desviado inteiramente de suas finalidades, seja por violência flagrante aos ditames legais que a norteiam, seja por descalabro administrativo.

Convém anotar, ainda, que as decisões finais dos dirigentes das entidades autônomas, salvo se a lei estatuir de modo diverso, não são suscetíveis de recurso para os órgãos controladores delas. Com efeito, o controle administrativo é instituído em nome de interesses da Administração Pública como um todo, e não como meio de defesa de interesses particulares. Sendo o ente autônomo uma pessoa jurídica e, por isso mesmo, exterior à linha hierárquica, suas decisões presumem-se definitivas. O Poder Central é estranho a elas. Se houve violação de direitos de particulares, devem os lesados dirigir-se à esfera jurisdicional que, ela sim, é a guardiã da legalidade. Eis por que, quando a lei prevê a existência de recursos dirigidos à Administração Central, contra atos da entidade autônoma, tais medidas de apelo se denominam 'recursos hierárquicos' impróprios.

A exposição feita descreve o panorama do controle administrativo, admissível no direito brasileiro, sobre os entes autônomos. Sendo criados por lei não há óbice que este desenhe um mecanismo tutelar mais ou menos extenso ou intenso. É o Legislativo quem decide sobre o grau de liberdade que deseja conferir ao ente autônomo, jungindo-o, pois, de modo mais estreito ou menos estreito à vigilância da Administração Central.

Há, contudo, segundo nos parece, um limite para a intensidade do controle, a partir do qual desnaturar-se-ia tanto este instituto, quanto a tipicidade própria das entidades autônomas, Á falta de óbice constitucional seria admissível, mas implicaria verdadeiro ilogismo. Referimo-nos ao 'poder de mando'. Este é o traço nuclear da hierarquia, do vínculo de subordinação.

O poder de mando traduz-se na expedição de instruções e de ordens concretas. Se à Administração Central fosse outorgado este poder, a personalidade dos entes autônomos - e personalidade é titularidade de direitos e obrigações - ficaria reduzida a uma expressão simbólica, faltando-lhe o essencial, que é justamente o poder decidir por si próprio, no que atina à própria esfera de direitos, sem estar, quanto a isto, adstrito a determinações alheias.

No Brasil, de fora parte a legislação concernente a cada uma destas entidades, oriundas normalmente das várias leis que as criaram - e que sempre respeitaram o aspecto assinalado - existem, 
12. Horacio Heredia - Contralor administrativo sobre los entes autarquicos, Buenos Aires, p. 211. na órbita federal, disposições gerais relativas ao controle dos entes autônomos. Encontram-se no precitado Decreto-lei n. 200. De acordo com este diploma, todas as entidades descentralizadas sujeitam-se à supervisão de algum ministério, na conformidade das respectivas finalidades:

Para cumprir esta função controladora, incumbe à supervisão ministerial, entre outros objetivos, assegurar-lhes autonomia, a obediência da legislação federal, harmonizar-lhes os programas de ação etc. E para atingir tais finalidades, quadram ao Ministro de Estado poderes como os de indicar ou nomear, conforme o caso, seus dirigentes, exigir relatórios e informações periódicas, realizar auditorias, fixar limites máximos de despesa com pessoal, fixar critérios para certos gastos, aprovar o orçamento dos entes autônomos e intervir por motivo de interesse público.

Convém ressalvar que no direito brasileiro, de regra, o controle efetivamente estabelecido nas várias leis atinentes aos diversos entes autônomos, tal como as próprias disposições estatuídas em norma geral sobre a matéria, cingem-se, sobretudo, a um controle repressivo e de legitimidade. São excepcionais as hipóteses de controle prévio e de mérito. As realizações concretas do direito positivo nacional praticamente cifram-se à exigência de aprovação preliminar de orçamentos e à fixação de alguns critérios gerais quanto a limites de despesa com administração, com pessoal ou com gastos de publicidade e relações públicas.

Nada obstante, podem assumir feições de muito maior intensidade e quando estabelecidas, são juridicamente não objetáveis. Isto é, nada embarga que o Legislativo as delineie sob quaisquer das modalidades inicialmente apontadas.

O que se acaba de dizer afina-se com as hipóteses em que o ente autônomo resulta de uma livre deliberação do Legislativo, em sua função legiferante ordinária. No caso brasileiro, as entidades autônomas (autarquias) estão todas nesta situação. Não é, entretanto, o caso da Costa Rica. Por existirem entes cuja autonomia é decorrente da Constituição, pensamos que os poderes de controle suscetíveis de serem fixados pelo Legislativo em prol da administração central serão necessariamente menores.

No que concerne aos entes autônomos mencionados na Constituição, sufragamos inteiramente as lições do eminente administrativista Eduardo Ortiz Y Ortiz, substanciadas nas seguintes conclusões, por ele assim sintetizadas: "El Estado Central no puede intervenir sobre el ente autónomo: Antes de que el ente se manifieste por primeira vez, mediante participación en los procesos preparatorios de sus decisiones, deliberaciones o actos, nimediante controles preventivos a priori, como las autorizaciones; Como jerarca, mediante el uso de los poderes fundamentales de la jerarqula, en iguales condiciones y iguales motivos que los proprios de tal tipo de relación orgánica; Como contralor de oportunidade, limitando la aplicación de critérios politicos, técnico-emplricos o culturales por parte de la institución; Como director de la gestión del ente autónomo, mediante imposición de lineamientos o de los programas 
Deveras, se foi a Constituição que estabeleceu o caráter autônomo de certas entidades, falece ao legislador ordinário a possibilidade de disciplinar a matéria em termos que configurem um amesquinhamento nos caracteres mais expressivos da liberdade autonômica administrativa. Fazê-lo importaria contrariar o pretendido no comando constitucional. Ora, o que há de mais expressivo na liberdade autonômica é, de um lado, o poder de agir sem prévio cerceamento e, de outro lado, a possibilidade de compor, motu proprio, seus critérios políticos, administrativos e técnicos. Segue-se que legislação inibidora ou minoradora desta gama de poderes implicaria coartar uma liberdade que se assenta em matriz constitucional, eminente, portanto. A fortiori, seriam incabíveis poderes de hieraquia, exercitados sob as condições e fundamentos deste vínculo, notadamente os de comando, quais os de impor instruções e ordens.

No que atina ao controle das entidades descentralizadas com personalidade de direito privado (empresas estatais, inclusive de capital mistol, as noções gerais dantes expedidas são aplicáveis com todas as restrições decorrentes da estrutura privada conferida à pessoa e, bem assim, do propósito de conferir-Ihes maior agilidade.

Então, por exemplo, a escolha de seus dirigentes resultará de eleição, na qual o Estado comparece enquanto acionista eleitor, sempre que os estatutos da entidade prevejam - como sói acontecer - esta forma de investidura. Inexiste prévia aprovação do orçamento da empresa, ao contrário do que se passa com os entes autônomos. O controle será, de direito, apenas repressivo, não envolvendo senão o exame de legitimidade.

Sem embargo, a condição de acionista controlador levará, na prática, a uma influência óbvia e decisiva quanto ao planejamento da ação da entidade e sua harmonização com a política geral do Governo, através de entendimento com os dirigentes ou da própria supervisão ministerial. Ainda quando os dirigentes sejam eleitos, não passarão, em termos reais, de simples prepostos da Administração Central. Assim, se de direito é maior a liberdade, de fato encontramse sob dependência tão acentuada quanto os entes autônomos.

Um último ponto relativo ao controle administrativo dos entes descentralizados merece consideração. A Carta Constitucional brasileira (art. 205) e a Lei General de la Administración Publica da Costa Rica (Lei n. 6.227, de 28 de abril de 1978, arts. 78 a 80) estabelecem que os conflitos entre a Administração Central, em nível de Ministério, e as entidades descentralizadas, ou destas entre si, serão resolvidos pelo próprio Executivo. No caso da Costa Rica, pelo Presidente da República e no caso do Brasil "pela autoridade administrativa na forma que a lei estabelecer".

O dispositivo brasileiro, por ser constitucional é insuscetv́el de discussão. Pode-se, apenas, reputá-lo inconveniente por subtrair deliberadamente à questão ao exame jurisdicional. Em face disto, se o próprio Executivo houver conflitado com a entidade descentralizada, por amesquinhar-Ihe direitos, competências, que Ihes hajam sido atribuídos por lei, poderá, graças ao poder de expedir a decisão final, fazer submergir a prevalência do princípio da legalidade. 
Dado que o dispositivo costarriquense é de nível legal e não constitucional, cremos que dever-se-á interpretá-lo, como solução de pendências ao nível administrativo, sem exclusão do exame da matéria ante a jurisdição competente, pelo menos no que respeita aos entes autônomos contemplados na previsão constitucional. A ser de outra forma, estaria consagrada a possibilidade do Executivo desfazer a autonomia concebida em nível supra-administrativo, o que seria inconveniente com princípios constitucionais.

Cabe, agora, breve referência sobre o controle por órgão auxiliar do Legislativo. Esta função, atribuída na Costa Rica à Contraloria General de la Republica (art. 183 da Constituição), no Brasil incumbe ao Tribunal de Contas (art. $70, \S 1$. da Carta Constitucional, de 1969).

No Brasil, o Tribunal de Contas, de ofício, ou mediante provocação das auditorias financeiras, ou do Ministério Público (chefiado pelo Procurador-Geral da República), se verificar a ilegalidade de algum ato ou despesa da Administração ou das entidades autônomas, determinará a sustação da execução do ato impugnado, caso não sejam, em prazo razoável que assinará aos responsáveis, adotadas as medidas necessárias ao fiel cumprimento da lei. Entretanto, falece-lhe tal poder em matéria de contrato. Nesta hipótese, solicitará ao Congresso Nacional que determine tal providência (art. 70 § 5.).

Diversamente da Contraloria General de la Republica, não Ihe cabe aprovar os orçamentos das entidades autônomas, mas apenas acompanhar-Ihes a execução. Também não lhe compete visar previamente ordens de pagamento, no que igualmente se afasta do regime costarriquense. No passado lantes da Carta de 1967, isto é, sob o império da Constituição de 1946) cumpria-Ihe tal função em matéria de contratos, cuja eficácia ficava pendente de registro prévio no Tribunal.

Finalmente, assiste ao Tribunal aprovar ou recusar aprovação, às contas anuais dos administradores públicos, inclusive de entes autônomos, quer sob o aspecto de sua exatidão material, quer sob o aspecto de legitimidade. Tal função é técnica, não tendo efeito conclusivo, pois deve ser encaminhado tal parecer ao Congresso Nacional que emitirá o Juízo definitivo.

São muito menos extensas as funções do Tribunal de Contas em relação às demais entidades descentralizadas lempresas do Estado). A lei disciplinadora da matéria (Lei n: 6.223, de 14 de julho de 1975, modificada pela Lei n. 6.525, de 11 de abril de 1978) praticamente limita seu controle à atividades de auditoria e aprovação ou reprovação das contas quanto à legitimidade, nada mais autorizando, salvo o encaminhamento ao Congresso Nacional de parecer sobre elas, afim de que o Legislativo as aceite ou rejeite, para fins de instauração das responsabilidades cabíveis.

\section{Responsabilidade do Estado por atos dos entes descentralizados}

O pressuposto de uma possivel responsabilidade do Estado é 
13. Revista de Derecho Publico, Universidad de Chile, n: 21-22, jan/dez. 1977, p. 152/153. um consectário lógico do Estado por atos de entidades descentralizadas liga-se, evidentemente, aos próprios termos da admissibilidade da responsabilidade do Estado por seus próprios atos.

Segundo entendemos, a responsabilidade do Estado, desde o advento do Estado de direito, sob o ponto de vista lógico, poderia independer de regra expressa para firmar-se, bem como dispensar o apelo a normas de direito privado para servir-Ihe de socorro, se faltassem disposições expressas de direito público.

Conforme nos parece, a idéia de responsabilidade do Estado é um consectário lógico do Estado de direito. A trabalhar-se com categorias puramente lógicas, a responsabilidade estatal é simples corolário de submissão do Poder Público ao Direito.

Deveras, a partir do instante em que se reconheceu que todas as pessoas, sejam elas de direito privado, sejam de direito público, encontram-se, por igual, sujeitas à ordenação jurídica, ter-se-ia que aceitar, a bem da coerência lógica, o dever de uma e outras - sem distinção - responderem pelos comportamentos violadores do direito alheio em que incorressem.

Ademais, como o Estado moderno acolhe, outrossim, o princípio da igualdade de todos perante a lei, forçosamente haver-se-á de aceitar que é injurídico o comportamento estatal que agrave desigualmente a alguém, ao exercer atividades no interesse de todos, sem ressarcir ao lesado.

Com efeito,é parte integrante da lei tanto o que consta de sua literalidade, quanto o que se contém no seu espírito, ou, segundo as palavras do eminente constitucionalista americano, Black, "o ditame implícito na lei é tanto parte de seu conteúdo como o que nela vem expresso".

Aliás, esta verdade, como máxima de interpretação, é proclamada desde tempos remotos. Em carta aos Coríntios, São Paulo averbou: "Littera enim occidit spiritus autem vivificat" (Epist. II, cap. 3, vers. 6). E Celsus deixou apostilado: "Scire leges non hoc est verba earum tenere sed vim ac potestatem" (Digesto, livro I, tit. III, fr. 17).

Donde, só aqueles apegados à mais simplista das interpretacões literais não podem perceber que a própria noção de Estado de direito impõe, como seu consectário natural, a responsabilidade pública por atos danosos a terceiros.

Acompanhamos, sem restrições, a lição de Eduardo Soto Kloss: "Quem diz direito diz, pois, responsabilidade". Perfilhamos ainda seu entendimento de que a idéia de república (res publica coisa pública), traz consigo a noção de um regime institucionalizado, isto é, onde todas as autoridades são responsáveis, "onde não há sujeitos fora do direito". Procede inteiramente a ilação que daí extrai: se não há sujeitos fora do Direito, não há sujeitos irresponsáveis; se o Estado é um sujeito de direitos, o Estado é responsável. Ser responsável implica responder por seus atos, ou seja: no caso de haver causado dano a alguém, impõe-se-lhe o dever de repará-lo ${ }^{13}$. 
14. La Reponsabilidad del Estado en Costa Rica, Separata da Revista de Ciencias Juridicas, n: 1 , 1963, p. 143e segs.
15. Conforme A. Nogueira de Sá, Do Controle administrativo sobre as autarquias, Braga, 1952. p. $65 / 66$.
Por tudo isto não cremos que se possa, no moderno Estado de direito, colocar qualquer dúvida sobre a existência do princípio da responsabilidade do Estado nos casos em que falte texto expresso dispondo sobre a matéria. Igualmente, parece-nos sem fomento jurídico satisfatório buscar apoio em regras de direito privado para sustentar-Ihe a existência, uma vez que a base para admiti-lo reside na própria espinha dorsal do Estado de direito.

No Brasil a Carta Constitucional de 1969 estatui, no art. 107, que: "As pessoas jurídicas de direito público responderão pelos danos que seus funcionários, nessa qualidade, causarem a terceiros". A redação é aproximadamente a mesma que constava da Constituição de 1946 e da Carta de 1967. Por força delas, prevalece no Brasil o entendimento de que está consagrada a responsabilidade objetiva, pois o teor do preceptivo citado não faz referência nem à ilicitude do ato, nem à culpabilidade ou dolo do agente. Quanto a nós, entendemos que a responsabilidade estatal é objetiva, quando o dano é produzido pelo Poder Público (atuação comissiva) ou quando o Estado sem ser, propriamente, o autor do dano, interfere decisivamente na linha de sua causação, e que é subjetiva quando o dano deriva de uma omissão do Estado.

Na Costa Rica, os artigos 9. e 41 da Constituição do país, como bem demonstrou Eduardo Ortiz Y Ortiz, já ofereciam supedâneo para a responsabilização estatal ${ }^{14} \mathrm{e}$, atualmente, por força da preciosa Lei General de la Administración Publica, de 28 de abril de 1978, em seus artigos 190 e segs., a matéria tem clara regulação no âmbito do direito público.

Diante dos pressupostos enunciados, caberia indagar se o Estado responde ou não por comportamentos das entidades descentralizadas. De logo, caberia descartar a hipótese de responsabilidade subsidiária, por quanto, sendo pessoas, seres distintos do Estado, é a eles que compete responder pelos comportamentos que adotam.

O que há de se pôr em pauta é a existência ou não de responsabilidade subsidiária do Estado.

Quanto aos entes autônomos, temos por certo que, exaustas suas forças para responder, emerge a responsabilidade subsidiária do Estado ${ }^{15}$.

Com efeito: o ente autônomo é pessoa de direito público. É criado pelo Estado afim de colimar objetivos estatais, públicos, que se tornaram próprios da pessoa autônoma, apenas porque o Estado Ihes atribuiu sua titularidade.

A persecução de seus escopos competiria ao Estado, se não houvesse recorrido à técnica de se fazer substituir por entidade sua e de caráter auxiliar.

As obrigações que a autarquia assume e a responsabilidade que lhe possa caber em razão de fato seu são suscitadas pelo exercicio de função posta pelo Estado em suas mãos, como dever a ser cumprido em proveito do mesmo Estado.

O interesse público - por cuja guarda e realização é responsá- 
vel o Estado - é a meta da entidade. Sua única razão de existir é a satisfação de objetivos públicos. Portanto, sendo desdobramento (embora personalizado), da pessoa estatal, não se lhe pode negar o caráter de agente indireto dela. Daí se segue que responderá por seus compromissos até o limite de suas forças. Vencidas, desaparece o patrimônio que mediava o Estado e o terceiro prejudicado, mas, emerge, naturalmente, o responsável último pelas funções públicas e pelas obrigações contraídas por ocasião de seu exercício.

O princípio da responsabilidade subsidiária do Estado pelos atos das autarquias é decorrência imediata do princípio da responsabilidade do Estado. Com efeito, exauridos os bens da autarquia, falta-lhe a condição efetiva de intermediário entre o Estado e o terceiro vinculado na relação, irrompendo, espontaneamente, a figura do criador da pessoa autárquica, em face do terceiro lesado por ação de entidade estatal.

Esgotado o patrimônio da autarquia, rasga-se o véu que apartava Estado e particular, ficando à descoberto aquele que operava por meio da autarquia.

Entendimento diverso, implicaria, franquear ao Estado meios de exonerar-se de sua responsabilidade graças à criação de pessoas auxiliares, às quais compete tanto quanto a ele, realizar misteres públicos, cuja própria natureza, pelos poderes que envolve, ensancha a possibilidade de causar danos muito mais extensos e vultosos do que os eventualmente gerados pelos particulares.

Já no que atina às demais entidades descentralizadas, isto é, às que não têm personalidade de direito público, parece-nos que cumpre estabelecer distinções. Consideramos cabível discernir entre as que prestam serviço público e as que exploram atividade econômica em paralelismo com a iniciativa privada.

Entendemos existir responsabilidade subsidiária do Estado e segundo os critérios de direito público, no caso das empresas do Estado que prestam serviço público propriamente dito.

Duas razões concorrem para esta inteligência. A primeira delas reside em que, se a lesão deriva do desempenho de um serviço que ao Estado caberia prestar, não se justificaria a liberação dele, dado que o agravo a terceiro só foi possível em razão do exercício de atividade pública que o Estado pôs em mãos da entidade que criou.

A segunda razão, igualmente ponderável, é a de que a prestação indireta, ou seja, por pessoa diversa do Estado, não pode ser meio transverso de exonerá-lo de uma responsabilidade - governada por princípios de direito público - a que se submeteria se houvesse mantido o serviço em suas mãos. Assim, se falecerem recursos à empresa estatal para responder pelos danos que cause, por ocasião de desempenho de serviço público, deverá irromper a pessoa do Estado como responsável último pelos misteres públicos.

Diferentemente, caso a empresa do Estado não seja prestadora de serviço público propriamente dito, mas exploradora de atividade econômica em paralelismo com a iniciativa privada, descaberá 
responsabilidade subsidiária do Estado. Isto porque, se houvesse a responsabilidade subsidiária, a empresa estatal teria um respaldo que as empresas particulares não têm. Ficariam, portanto, em situação desigual.

Ora, nos regimes assentados sobre a livre iniciativa, não é de admitir outorga de vantagens às empresas econômicas do Estado, pois isto implicaria inverter a tônica do sistema. E é evidente que, nos empreendimentos de grande vulto, os particulares sentir-se-iam mais seguros em contratar com uma empresa do Estado, caso houvesse responsabilidade subsidiária deste, do que com uma empresa particular. E nisto estaria sendo subvertida a lógica do regime.

\section{Bibliografia}

1. GALVIS, Alvaro Tafur. Las entidades descentralizadas. Bogotá, Editorial Temis, 1977, p. 38-49.

2. ORTIZ y ORTIZ, Eduardo. La autonomia administrativa costarricense. Separata de Revista de Ciências Jurldicas, Braga, Ciências e ARS Editorial, 1967, p. 122.

3. ESTUDOS de direito administrativo. Coimbra, Atlântida Editora, 1968. p. 9.

4. FAGUNDES, Miguel Seabra. Controle dos atos administrativos pelo Poder Judiciário. 3 ed. Rio de Janeiro, Forense, 1957, p. 17.

5. QUEIRO, Afonso Rodrigues. A teoria do desvio do poder em direito administrativo. s.I., Coimbra Editora, 1940. p. 19.

6. LIMA, Rui Cirne. Princĺpios de direito administrativo; parte geral. 3 ed. Porto Alegre, Ed. Sulina, 1954. p. 22.

7. FLEINER, Fritz. Les principes généraux du droit administratif allemand. Trad. de Ch. Einsenmann. Paris, Librairie Dellagrave, 1933. p. 87.

8. HEREDIA, Horacio. Contralor administrativo sobre los entes autárquicos. Prol. de Rafael Bielsa. Buenos Aires, V. Abeledo, 1942, p. 22.

9. VALLES, Arnaldo de. Elemento del dirltto amministrativo. 3 ed. Padova, CEDAM, 1956. p. 89.

10. ALESSI, Renato. Sistema istituzionale del dirftto amministrativo italiano. 3 ed. Milano, A. Giufrè, 1953. p. 138-9.

11. RIVERO, Jean. Droit administratif. 2. ed. Paris, Dalloz, 1973. p. 277-9.

12. LAUBADĖRE, André de. Traité de droit administratif. 3 ed. Paris, Librairie Générale de Droit et de Jurisprudence, 1963. v. 1, p. 90.

13. VEDEL, Georges. Droit administratif. 2 ed. Paris, Presses Universitaires de France, 1958. v. 2, p. 418.

14. DIREITO administrativo. 6 ed. Lisboa, s. ed., 1963. p. 192.

15. HEREDIA, Horacio H. Contralor administrativo sobre los entes autárquicos. Prol. de Rafael Bielsa. Buenos Aires, V. Abeledo, 1942. p. 61-2.

16. ORTIZ y ORTIZ, Eduardo. La autonomia administrativa Costarricense. Separata da Revista de Ciencias Jurldicas, Braga, Ciências e ARS editorial, 1967, p. 122.

17. REVISTA DE DERECHO PUBLICO. Chile, Universidad de Chile (2122): 152-3, jan./dez. 1977.

18. LA RESPONSABILIDAD del Estado en Costa Rica. Separata da Revista de Ciencias Jurldicas, Braga, Ciencias e ARS Editorial (1): 143, 1963.

19. SÁ, A. Nogueira de. Do controle administrativo sobre as autarquias. s. I., 1952. p. 65-6. 